\title{
LOS PLATEROS ZARAGOZANOS EN EL SIGLO XV
}

\author{
MARÍA ISABEL FALCÓN PÉREZ \\ Universidad de Zaragoza
}

La platería zaragozana gozó de merecida reputación durante la Baja Edad Media. Sus artífices, los argenteros, estaban agrupados en una cofradía, fundada el 2 de agosto de 1420, bajo la advocación de San Eloy y con sede en el monasterio de Nuestra Señora del Carmen de la ciudad'. Sin embargo la pertenencia a la misma no era obligatoria para ejercer esta profesión en la capital del Ebro, como claramente consta en un párrafo intercalado entre los puntos XXVI y XXVII de los estatutos ${ }^{2}$.

Las primeras ordenanzas conservadas para esta industria artesanal en Zaragoza las dio a conocer María Dolores Mateu Ibars $^{3}$ y son de gran interés pues nos permiten adelantar en casi un siglo los requisitos de esta artesanía. El 9 de noviembre de 1415, reunido el capítulo y consejo de la ciudad, los dirigentes zaragozanos se plantearon que en el oficio de la platería local se cometían muchos fraudes, a los que había que poner coto.

\footnotetext{
'Las ordenanzas fueron aprobadas por la reina doña María, esposa de Alfonso V. Aparecen en el registro de Cancillería n" 3116 , fols. 38-43v, del Archivo de la Corona de Aragón (ACA). Existe una copia notarial por duplicado. de finales del siglo XVII, en el Archivo Municipal de Zaragoza (AMZ), que es el texto que hasta ahora han utilizado los estudiosos de esta arte. El documento del ACA, que tuve la suerte de encontrar, lo he publicado: cfrr. M.I. FALCÓN PÉREZ, Ordenanzas y otros documentos complementarios relativos a las Corporaciones de oficio en el reino de Aragón en la Edad Media, Institución Fernando el Católico, Zaragoza, 1997, doc. 118.

${ }^{2}$ M.I. FalCón PÉREZ, Obra y documento citados, pp. 229-230.

"Una copia de los 'capitoles e ordinaciones' del oficio de argenteria de la ciudad de Zaragoza de 1415". En "Homenaje a Don José María Lacarra de Miguel en su jubilación del profesorado". IV. Zaragoza, 1977. pp. 31-41. El documento está en la sección de Procesos del ACA. También publicado por M.I. FalCón PÉREz, Ordenanzas y otros docimmentos, doc. 112. 
Consultadas las formas por las que se regía el arte en las ciudades de Barcelona y Valencia, decidieron promulgar a su vez una normativa que pusiera fin a los abusos. Este reglamento, que afectaba no sólo a la capital sino también a las poblaciones de su término municipal, es de carácter técnico: calidad de los metales, fidelidad en pesos, creación del punzón de la plata de la ciudad, y muchos otros aspectos que pasamos a comentar:

En primer lugar se ocupan de la ley del oro. Los anillos, sortijas y broches que pesen una onza o menos, se harán de oro bajo, el llamado oro de tari $^{4}$, de 17 quilates, es decir, que de 24 partes (oro puro) había siete de aleación; entre una y cinco onzas, la ley obligatoria es 18 quilates y a partir de cinco onzas de peso, la joya deberá ser hecha con oro de 20 quilates poco mas o menos, advirtiendo que estas pequeñas variaciones sean juzgadas por los veedores, tanto para el peso como para la ley.

La obra de oro había de ser marcada con el marco del oro de Aragón, tanto si la hacían en Zaragoza como si la traían de fuera a vender aquí. El profesor Mateu Llopis publicó un precioso texto de 1417 acerca del marco del oro fino en toda la señoría del rey de Aragón, que era idéntico para todos sus dominios y conocido como "marco de Perpiñán", cuya ley era de 24 quilates; $^{5}$ en estas ordenanzas de 1415, como vemos, se tolera una calidad más baja e incluso, un poco más adelante, se reconoce que la ley mínima de la obra de oro admitida en Zaragoza es 16 quilates. El "peso del contrast" para monedas de oro en Zaragoza aoarece citado en un pregón del año $1502^{6}$.

Las piedras preciosas, como los diamantes, sólo podían ser engastadas en joyas de oro, en tanto que otras piedras y cristales, aunque estuvieran talladas en forma de diamante, no estaba permitido incrustarlas en alhajas de oro, sino de cobre o de latón, para evitar cualquier tipo de engaño al comprador. Es decir que, según estas ordenanzas, las piezas de oro no podían llevar piedras falsas. Y por supuesto, la plata dorada no era

\footnotetext{
${ }^{4}$ Aureum monetae Sicilianae: es la moneda de curso legal en esta época en Nápoles y Sicilia. La aleación estaba compuesta de diez partes de oro, diez de plata y cuatro de cobre.

${ }^{5}$ Felipe Mateu y Llopis. Acerca de los marcos de los países de la Corona de Aragón y: en especial, del de Valencia, "Numisma", XXIII-XXIV (1973-74), p.413.

${ }^{6} \mathrm{AMZ}$, Ms. 34. Pregones de los años 1499 a 1514 (Pre-4), fols. 93-94.
} 
lícito venderla como oro, ni mucho menos el latón ${ }^{7}$. Si un platero elaboraba vajillas de cualquier materia que no fuese oro o plata, había de señalar con letras capitales la clase de metal de que estaban hechas, bajo graves penas y pérdida de los objetos.

La mayor parte de las ordenanzas se refieren a la obra en plata, de la que distinguen la obra grossa y la obra menuda. La primera la forman los utensilios de la mesa, la vajilla, como son los vasos (picheres), copas, vasijas (bacines), platos, fuentes (plateres), escudillas, tazas, cucharas, jarras (terraças), etc, y los objetos de uso litúrgico, tales como custodias, cálices y cruces. La obra grossa se tenía que marcar a ley de buenos torneses viellos, que supone plata de ley de 11 dineros y 6 granos $^{8}$. La obra menuda estaba formada por armas blancas: espadas, estoques, dagas, puñales... y por algunas joyas, como collares, cadenas, cintas y texeles. Estos objetos se tenían que marcar a ley de barceloneses viellos, dineros cuya aleación contenía plata de ley de 11 dineros. Ley que se dispone haya de mantenerse constante en el futuro en ambos casos, aunque se advierte poco más o menos, dejado esta oscilación a juicio del veedor, que la marcará o no lo hará si la encuentra incorrecta ${ }^{9}$. Un poco más adelante la ordenanza reconoce como ley de la ciudad para la plata la de 11 dineros, sin especificar la clase de obra.

Respecto a los marcos, cuños o punzones de la plata, demostrativos en todas partes de la garantía de la ley y del lugar de procedencia de las piezas, establecen que haya en Zaragoza dos, uno para la obra grossa y otro para la menuda, llamados respectivamente marquo mayor y marquo menor. El primero figuraba un león y las letras CESARAUGUSTA. El segundo, medio león y las mismas letras capitales. Probablemente el mayor es el que recoge

\footnotetext{
${ }^{7}$ Por una cadena de latón, que se hizo pasar por oro, tenemos un largo e interesante proceso incoado ante los mayordomos de la cofradía de Santa María de Predicadores o de los Mercaderes de Zaragoza por Martín de Exea contra un corredor apelado Ferrando de Far, quien aprovechando la ausencia del mercader pidió un importante préstamo a la esposa de éste, dando como garantía una cadena de latón, que aseguró era de oro. Cfr. M.I. FalCón Pérez, Ordenanzas y otros documentos, doc. 218 , de 26 de septiembre de 1471.

${ }^{8}$ Esta moneda es el gros tornés, acuñada por Luis IX de Francia, cuya ley era de once dineros y medio y equivalía a un sueldo jaqués, o mejor dicho a doce dineros de vellón. puesto que el sueldo nunca se acuñó.

${ }^{9}$ Angel SAN VICENTE recoge un documento judicial aragonés del siglo XVII, que reconoce este principio de elasticidad en la proporción de la plata: "con el poco más o menos que se ha acostumbrado y permite, conforme a las leyes del reyno de Aragon". Cfr. La platería zaragozana en el Bajo Renacimiento (1545-1599), I, Zaragoza, 1976, p. 38.
} 
Juan Francisco Esteban y que data en el siglo XVI, hasta 1541. Ha localizado otro, semejante pero más pequeño, que él fecha hacia 1431-1470, que podría ser el cuño menor ${ }^{10}$.
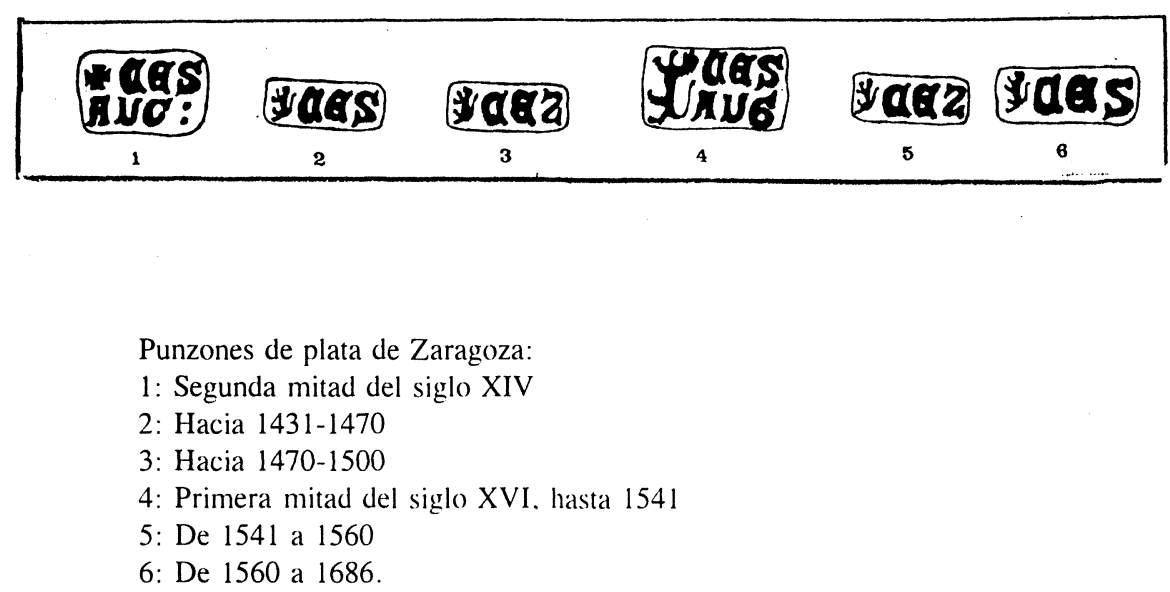

Según J.F. Esteban LORENTE".

En 1471 los jurados y el oficio de plateros acordaron hacer un punzón nuevo (no explican cual de los dos). Encargan su elaboración a maestre Juan de Bruselas, platero, que habrá de contar con la presencia, durante su confección, de varias personas: Andrés Marín, marcador, Jayme Nadal, platero, mayordomo bolsero y guardián de la llave de la caja del marco, Juan del Frago, mayordomo, Mateo Roch y Gonzalo de Aguilar, consejeros del oficio, Luis Mallol, platero y Castán de Lacambra, andador de los jurados; todos juraron que estarían presentes en la producción del

${ }^{10}$ J.F. ESTEBAN LORENTE, El punzón de la platería y de los plateros zaragozanos desde el siglo XV al XIX, "Cuadernos de Investigación (Geografía e Historia)". 2 (Logroño, 1976), p. 86

"Dibujados por Juan F. EsTeBAN LORENTE y publicados en su obra: El punzón de la platería y de los plateros zaragozanos desde el siglo XV al XIX. "Cuadernos de Investigación (Geografía e Historia)", 2 (Logroño, mayo de 1976), p. 86, y en la "Gran Enciclopedia Aragonesa", X, p. 2775, que amablemente me ha permitido reproducirlos aquí. 
punzón y que una vez terminado y aprobado desharían las puntas con que se había fabricado así como el punzón viejo ${ }^{12}$.

Los plateros tenían obligación de presentar la pieza por ellos hecha al veedor para que éste la reconociera y si se ajustaba a la ley la marcara con el punzón oficial de la ciudad. Si la consideraba defectuosa la rompía y rota la devolvía al platero para que la rehiciera, de tal modo que el artífice sólo podía llevarse el objeto que había traído marcado o quebrado. La misma obligación recaía sobre los que trajeran a Zaragoza piezas de plata para vender. El veedor era multado con cien sueldos si no cumplía a rajatabla este precepto; de ese modo, cualquier pieza sin marcar era considerada falsa automáticamente y por lo tanto requisada. El valor de la plata de ley de once dineros era de 16 sueldos y 6 dineros la onza (a 132 sueldos el marco), en el siglo $\mathrm{XV}$ y en el $\mathrm{XVI}^{13}$.

Las ordenanzas de 1415 regulan el cargo de veedor o inspector. Este oficial estaba autorizado a entrar una o dos veces por semana en todas las tiendas y talleres de argenteros de plata o de oro y analizar el metal que allí se encontraba. Para este trabajo podía contar con la ayuda de uno o dos plateros a modo de subinspectores, a su elección, los cuales no podían negarse a colaborar. Y los dueños de los obradores tenían que facilitarles el trabajo, abriendo arcas y cajas y mostrándoles todo aquello que quisieran ver, sin oponer resistencia ni mucho menos injuriar o agredir al veedor, bajo fuertes castigos.

El veedor era el guardián del marco o cuño de la plata; había de tener balanzas finas y una pila de marco de peso de setze marchos por patron e original para afinar una vez al año los marcos y balanzas de los plateros ${ }^{14}$. Este marco original solo podía utilizarlo para dicha operación de afinar, no para marcar continuamente, a fin de que el uso cotidiano no lo desgastara. El veedor estaba obligado al tomar posesión de su cargo de jurar en poder de los jurados de Zaragoza de haverse bien e leyalment en el dito officio, estando sometido a la jurisdicción de estos regidores en caso de incurrir en falta. La tasa por marcar, a la que las ordenanzas hacen muchas

\footnotetext{
${ }^{12} \mathrm{AMZ}$, Actos Comunes de 1471, fol. 81.

${ }^{13} \mathrm{~A}$. SAN VICENTE, La platería zaragozana, I, p. 38.

${ }^{14}$ La pila era una caja con su correspondiente tapa donde se guardaban los marcos y demás utensilios para la operación. En la cara interior de la tapadera solía estar grabado el contenido de la misma.
} 
referencias en cuanto al reparto y aplicación, no queda señalada en la documentación del siglo XV consultada.

Para el cumplimiento de su misión, el veedor estaba obligado a tener dos rieles o vergas d'argent, cada uno de peso de cuatro onzas; la primera de ley de once dineros y seis granos y la segunda de ley de once dineros, que constituirían los patrones para calibrar la obra gruesa y la menuda respectivamente antes de marcarla. Los regidores disponen que estos rieles o vergas los tiene que hacer, cada uno de la dicha ley, un maestro de Valencia o de Barcelona.

En este primer momento el cargo de veedor recae en el platero Francés Spelt, que será el primer marcador conocido de Zaragoza. A él entregaron los marcos de hierro de la ciudad, el mayor y el menor, con los que le ordenaron marcase respectivamente la obra gruesa y menuda de buena ley que le fuera presentada. Y considerando que la tenencia de marcos, balanzas, rieles, toques y demás utensilios para probar la ley del oro y la plata suponía tener en custodia un material muy valioso, el veedor tenía que hacer un depósito o fianza de cien florines ${ }^{15}$. A cambio se le autoriza a cobrar por su trabajo "las tasas que se acostumbran a percibir por marcar los metales preciosos", cuya cuantía no indican (lo que demuestra que ya se marcaban con anterioridad y se daba por sabido) ${ }^{16}$. Francés Spelt aceptó el cargo, recibió los marcos grande y pequeño de hierro y prestó el juramento preceptuado. Antes de marcar, para comprobar la ley, el marcador tenía que sacar de la pieza tres o cuatro borins o rayeduras, es decir, raspaduras, que era la porción de metal que analizaba.

El 14 de noviembre de dicho año 1415 fueron pregonadas estas ordenanzas por la ciudad. Pasados algunos días, el 5 de diciembre, los representantes de los plateros comparecieron ante el capítulo y consejo,

\footnotetext{
15 " Et considerado quel dito veedor ha grant carga e treballo cerca el exercicio e execucion de las ditas ordinaciones hoc encara grant expensa, por tanto como por vigor de las anteditas ordinaciones el dito veyedor y es tenido tener patrones ciertos de marcos, balanças e rieles siquiere bergas d'oro e d'argent pora pesar, atoquar e provar el oro e el argent de qual ley y es, pora lo qual segunt se troba por verdat ha menester vistrayer e tener el dito veyedor cient florines de cabal o mas pora los ditos patrones". Cfr. M.I. FALCón PÉrez. Ordencinzas y otros documentos, doc. 112 citado.

${ }^{16}$ En 1599 se determina la cuantía de dichas tasas: "que los dichos marcador y mayordomo bolsero del presente dia adelante no puedan llebar ni lleven mas de dos dineros por cada pieça de plata que marcaren, aunque aya en ella mucha pieça burilada, como suelen tener los saleros, o otros vasos semejantes de muchas pieças de qualquiere cantidad y calidad que sean. Y por una cuchara un dinero". Cfr. A. SAN VICENTE, La plateria zaragozana, I, p. 41.
} 
solicitando algunos cambios en las mismas, que no fueron aceptados excepto uno: que hubiese otro veedor más junto a Frances Spelt, pero advirtiendo que éste sería el guardián de los cuños y por tanto el marcador, recibiendo el otro el título de compañero y careciendo de capacidad para marcar. El segundo veedor o compañero sería elegido por los jurados de una terna propuesta por los plateros y habría de prestar también juramento. Prevén para el futuro que el marcador sea siempre uno de los dos veedores.

Dichos veedores desaparecen pronto, sustituidos por los mayordomos. Tanto las ordenanzas de 1420, como la sentencia arbitral de 1443, que enseguida veremos, no hacen ninguna referencia a veedores, sino a mayordomos. A mayor abundamiento, en 1476 los jurados autorizan expresamente a dichos mayordomos del oficio de plateros para que puedan visitar los talleres y tiendas de mercaderes, freneros, espoloneros, puñaleros, cinteros y cualesquiera otros artífices que fabriquen cadenas, correas, anillos, cruces y cualquier otro objeto de latón o hierro, para comprobar que ponen en letras capitales el tipo de metal usado, a fin de no hacerlo pasar por plata $^{17}$.

La caja del marco de la plata era encomendada por los jurados al marcador, elegido por ellos de entre una terna presentada por la cofradía. En 1472 contenía "dos punzones de marcar, uno grande y otro pequeño, y dos rieles de plata, el uno de obrar y el otro de marcar, para hacer el ensayo de obrar y marcar"; el marcador Andres Martín la restituye a los jurados en septiembre del citado año y ellos la encomiendan a García de Santa Fe, platero y vecino de Zaragoza ${ }^{18}$. La llave de la caja la custodiaba el mayordomo bolsero ${ }^{19}$.

A mediados del siglo XVI el marcador seguía siendo nombrado por los jurados tras consultar a la cofradía: "havida legitima información de los plateros de aquella de la sufficiencia y bondad de algunos del dicho officio", y recibía de los regidores municipales "una caxilla con dos punçones de la marca de la dicha ciudad, con dos bossellos y dos pedaços de la plata que se marca para patron, y una caxita que esta dentro de la dicha primera caxa para echar los dineros que se sacan de la dicha marca, y dos buriles para

\footnotetext{
${ }^{17}$ M.I. FAlCón PÉrez, Ordenanzas y otros documentos, doc. 222.

${ }^{18} \mathrm{AMZ}$, Actos Comunes de 1472, fols. $141 \mathrm{v}$ y 145 (sesiones de 10 y 15 de septiembre). Mallol.

${ }^{19} \mathrm{AMZ}$, Actos Comunes de 1440, fol. $21 \mathrm{v}$. El mayordomo bolsero es el omnipresente Luis
} 
sacar las burilladas, y un cepo y una staca de cucharetas, y un tas de ondones, y un martillo, y un fornillo donde se sacan las burilladas, y una raspa"; la llave de dicha caxilla era confiada al mayordomo bolsero de la hermandad, a quien, como anteriormente, se vincula el acto de marcar. El marco patrón se conservaba por duplicado, estando el otro ejemplar bien guardado en el archivo municipal ${ }^{20}$.

El 2 de agosto de 1420 la reina doña María aprobó las ordenanzas constituyentes de la cofradía de San Eloy, de los aurifficum sive argenteriorum de Zaragoza, elaboradas por los propios maestros del oficio, que a tal fin le habían sido presentadas ${ }^{21}$. Estas ordenanzas son de tipo religiosobenéfico-asistencial, muy semejantes a las de la mayoría de los oficios artesanales existentes en las diversas ciudades y villas de los dominios del rey de Aragón. Su principal preocupación son los asuntos caritativos y de previsión social y las obligaciones religiosas y devocionales de los cofrades, finalidad primordial de las cofradías ${ }^{22}$.

Los órganos de gobierno que establece este reglamento son: el capítulo o asamblea de cofrades, dos mayordomos, que eran los mandatarios supremos, elegidos anualmente en el capítulo general ordinario (el día siguiente de San Eloy, el 2 de diciembre) y un andador, de permanencia en el puesto indeterminada, que estaba encargado de las convocatorias, avisos y de tomar pequeñas prendas (las de mayor cuantía eran competencia del verguero del zalmedina de la ciudad). La sede de la hermandad se fija en el Monasterio de Santa María del Carmen. Se dispone una caja común, donde se recogerán las aportaciones de los cofrades (cuatro sueldos y cuatro dineros al año cada uno para limosnas y cinco sueldos en testamentaría), las tasas de ingreso y las multas en metálico, y de donde se realizarán los pagos y limosnas previstos por los estatutos. Uno de los mayordomos guardará la caja y el otro la llave, de modo que sólo pueda abrirse en presencia de

${ }^{20}$ A. SAN VICENTE, La platería zaragozana, I, p. 40.

${ }^{21}$ M.I. FALCÓN PÉREZ, Ordenanzas y otros documentos, doc. 118. Han sido estudiadas por Angel SAN VICENTE, La platería zaragozana, I, pp. 15-24. Y por Juan Francisco ESTEBAN LORENTE, Ordenanzas que rigen a la platería zaragozana desde 1420 a 1742. En La ciudad de Zaragoza en la Corona de Aragón, "X" Congreso de Historia de la Corona de Aragón. Comunicaciones", Zaragoza, 1984, pp. 246-250.

"2Además de los comentarios de los dos autores citados en la nota enterior, cfr. M.I. FALCÓN PÉREZ, Las cofradías artesanales de la Edad Media. Aspectos religiosos y sociales, en La manufactura urbana i els menestrals (ss. XIII-XVI). IEB, Palma de Mallorca, 1991, pp. 193222. 
ambos; se ordena a los mayordomos que lleven un libro de caja donde anoten puntualmente los ingresos y gastos, y que rindan cuentas al final de su año de mandato.

La pertenencia a la cofradía no parece ser requisito indispensable para establecerse como platero en Zaragoza. Las tasas de entrada se fijan en diez sueldos jaqueses, y si es in articulo mortis en veinte. Pero todos los plateros con tienda abierta en la ciudad, tanto cofrades como no, estaban obligados a prestar juramento ante los mayordomos de obrar de buen oro e buen argent y cumplir las ordenanzas de la platería zaragozana; los que acababan de llegar, además del juramento tenían que pagar diez sueldos a la caja de la cofradía, de los primeros que ganaran, y si persistían en mantenerse fuera de la almosna habían de pagar cada año doce dineros para la caja común ${ }^{23}$.

El trabajo de inspección que veíamos en las ordenanzas de 1415 encomendado al marcador y a otro veedor, aquí queda a cargo de los dos mayordomos, acompañados por dos cofrades. La ejecución de las penas será misión de un oficial real, dejando de lado la habitual intervención de los jurados, capítulo y consejo de la ciudad. Incluso el preceptivo juramento lo prestarán los mayordomos entrantes en poder de los salientes, según esta ordenanza de 1420. Ese mismo día la reina lugarteniente dictó dos privilegios complementarios de las ordenanzas, que no hacen sino reiterar los párrafos destinados a los plateros forasteros o recién llegados y a los que no pertenezcan a la cofradía, recalcando las tasas que tenían que pagar, a las que ya me he referido. Además ia regente vuelve a repetir íntegramente el artículo dedicado a la inspección. Sin embargo hay un párrafo nuevo muy interesante, que se refiere al marcador de la plata, no mencionado en el reglamento: dice la reina que con estas ordenanzas no quiere hacer perjuicio al marcador que tiene el marco de la ciudad, sino que declara expresamante que se mantenga como estaba, si bien sometido a los mayordomos y capítulo como todos los demás plateros ${ }^{24}$. Por tanto contamos desde este momento con un marcador, ya existente, y dos mayordomos, pero ningún veedor.

\footnotetext{
${ }^{23}$ Es frecuente encontrar el término almosna como sinónimo de cofradía.

$2+1 \mathrm{Nec}$ etiam volumus fieri preiudicium officio marchatoris seu illius qui tenet pro dicta civitate Cesarauguste marchum civitatis eiusdem, imo illud iuxta privilegia vel ordinaciones civitatis ipsius remaneat sicut prius. Et hoc non obstante dictus marchator vel qui dictum tenebit marchum et eius operarii sint omnibus supradictis subiecti et summissi sicut alii argentarii vel operarii supradicti". M.I. FAlCón PÉREZ, Ordenanzas y otros documentos, doc. 119. Y doc. 120 , mera confirmación.
} 
He encontrado entre un montón de papeles sueltos del Archivo de Protocolos zaragozano un documento, sin fecha, que tenía anotado en una cubierta de papel "Estatutos de argenteros, 1420". Al leerlo descubrí que nada tenía que ver con las ordenanzas de doña María que acabo de comentar, sino que se trataba de una sentencia arbitral sobre el sistema electoral de la cofradía de San Eloy, forma de realizar las comidas de hermandad y algunos otros aspectos de régimen interno ${ }^{25}$.

Este documento me ha planteado muchas dudas en cuanto a su datación. El notario que lo hace, aunque no figura testificando el documento, creo que es Pero Martinez de Alfocea, que acababa de sustituir recientemente al fallecido Alfonso Lajusticia. Desconozco la fecha de la muerte de éste, del que no se conserva, que yo sepa, ninguna nota. En cuanto al anterior, hay protocolos de notarios de este nombre desde 1431 hasta 1489 .

Otro personaje esclarecedor es el pintor Bonanat Çaortiga, al que los plateros habían encargado el retablo de San Eloy para el Monasterio del Carmen, obra que en este documento le retiran. El artista está documentado en Zaragoza y otros pueblos de Aragón desde 1409 hasta 1457. El año 1443 casa a su hija, Maria Lopez Çaortiga, con Johan Sanchez, platero -spasser-, actuando como testigo Pascual Ximenez de Agüero ${ }^{26}$, que es uno de los tres argenteros que le habían mandado hacer el retablo de San Eloy en fechas anteriores al documento que nos ocupa, y que en 1440 salió como fiador del pintor en un negocio. En 1446 Bonanat es encarcelado, junto a su hijo Nicolás, también pintor, por acuchillar a un platero llamado Miguel de Monreal $^{27}$. El mayor número de encargos que le hacen a Bonanat distintas entidades y particulares se concentra en los años 1438-1443, que sin duda coinciden con el cénit de su fama.

Pascual de Ahuero, Agüero o Ximenez de Agüero, que de todas estas formas es citado, figura entre los plateros que solicitaron a la reina doña María en 1420 que les autorizase a fundar la cofradía de San Eloy. Tenemos muchas noticias sobre él, la principal es que trabaja, con su hijo Francisco, entre 1442-1443 para el arzobispo don Dalmau de Mur. Muere

\footnotetext{
${ }^{25}$ M.I. FalCón PÉREZ, Ordenamzas y otros documentos. doc. 144.

2629 de noviembre de 1443. AHPZ, Ms. 3950, Cuadernillo de Pero Martinez de Alfocea de ese año, fols. $11 \mathrm{v}-13$.

${ }^{27} 24$ de julio de 1446. Ese mismo día fïrman carta de paz. Pero nos está indicando algún contencioso con este oficio. AHPZ, Ms. 1944. Protocolo de Alfonso Martinez, 1446, fols. 199$200 \mathrm{v}$.
} 
el 23 de octubre de 1443, que me ha servido de fecha ante quem para el documento, puesto que en el mismo actúa de árbitro y por lo tanto está vivo.

Otro dato revelador es la noticia que proporciona este manuscrito de que Alvaro Sánchez, mayordomo hasta entonces, acaba de morir, por lo que es sustituído por Luis Mallol, bolsero, hasta las próximas elecciones. Alvaro Sánchez también figura en el documento fundacional de 1420 como mayordomo, y en 1440 como mayordomo bolsero ${ }^{28}$. Esta podría ser la fecha post quem mas cercana que he podido conseguir.

He rastreado al resto de los personajes que aparecen en el documento, y los he podido documentar copiosamente siempre en fechas cercanas a 1440-1443, pero no creo que sean necesarias más precisiones, de modo que la fecha mas aproximada que yo daría es el año 1443, antes de octubre.

La repugnancia a acudir a los tribunales que afectaba a la población bajomedieval, les llevaba a aceptar en sus discrepancias el sistema de "arbitraje", que significaba la sumisión a la sentencia de dos árbitros, puestos uno por cada parte, comprometiéndose éstas a pagar severas multas de no acatarla; la documentación notarial está llena de arbitrajes. En el caso que nos ocupa, el pleito lo habían iniciado dos plateros cofrades, Juan Figueras y Jaime Nadal, contra los rectores de la cofradía por disentir en el modo de empleo del dinero de la caja común, ya que ellos dos pretendían que se dedicara íntegramente a limosnas y previsión social. Los árbitros nombrados fueron otros dos plateros, Pascual Ximenez de Agüero y Juan de Pisa, el primero representando a la cofradía y el segundo a los recurrentes. Aunque no se explica el motivo, intuyo que fue el encargo del citado retablo para la capilla de San Eloy, en el Monasterio del Carmen, que tres plateros, alegando poder para ello, habían hecho al pintor Bonanat Çaortiga por un importe de 100 florines. Por tal motivo los dos discrepantes habían "manifestado" la caja de la cofradía ante el Justicia de Aragón, en cuyo poder había sido tomada, de modo que la cofradía no podía disponer de sus recursos, con todos los problemas que esto acarreaba.

Los árbitros quitan el encargo al citado pintor y dan poder a Juan de Pisa, árbitro, y a Pascual Salvador, mayordomo de la cofradía, para que contraten para hacer el controvertido retablo al artista que mejor les parezca, autorizándoles a gastar en ello hasta 400 sueldos, que se pagarán de la parte de las tasas de "marcar la plata" que corresponden a la cofradía y, si no es

\footnotetext{
${ }^{28} \mathrm{AMZ}$, Actos Comunes de 1440 , fols. $21 \mathrm{v}$ y $23 \mathrm{v}$.
} 
bastante, de la propia caja común. Y ordenan a los dos discrepantes que retiren la denuncia y "manifestación" ante el Justicia, de manera que la cofradía pueda recuperar su caja que quedará depositada en poder de Luis Mallol, nuevo mayordomo bolsero, que sustituirá hasta las siguientes elecciones al recientemente fallecido Alvaro Sánchez. El otro mayordomo es Pascual Salvador, al que se ha encomendado buscar pintor para el retablo. Luego se ocupan pormenorizadamente de la forma de ejercer el socorro a los cofrades venidos a necesidad, en cumplimiento de uno de los principales fines de las cofradías medievales ${ }^{29}$.

Pero además de la sentencia, el documento contiene unas interesantes ordenanzas sobre el sistema electoral que en el futuro se habrá de seguir en la cofradía de San Eloy y que tendrán que aprobar los jurados, capítulo y consejo de la ciudad ${ }^{30}$. Así que nos encontramos con un cambio respecto a las ordenanzas de 1420 , que parecen prescindir de los regidores municipales, como queda dicho más arriba. De todos modos, a juzgar por los testimonios documentales que se conservan, la intervención de los jurados queda patente con anterioridad: el 15 de enero de 1440 comparece ante los mandatarios del concejo el maestro platero Juan Bover, marcador y guardián del marco de la plata, que presenta a Luis Mallol como mayordomo bolsero y a Alvaro Sánchez como mayordomo y compañero de éste; ambos juran el cargo en poder de los jurados y a Luis Mallol le encomiendan las llaves de la caja del marco ${ }^{31}$.

En la sentencia arbitral de Pascual Ximenez de Agüero y Juan de Pisa hay, como queda dicho, unos "capitoles para los jurados" que modifican el sistema electoral y que someten a la aprobación de los mandatarios municipales. Los cargos a proveer por elección anual son: mayordomo, consejeros, escribano y limosnero, todos ellos en capítulo general, con asistencia de la totalidad de los cofrades y en el monasterio del Carmen.

El procedimiento es el siguiente: una vez sentados los plateros por orden de antigüedad en la cofradía, el notario del concejo o, si lo hay, el notario real propio de la cofradía habrá de escribir los nombres de todos los presentes. A continuación echará mano de unas capsetas de madera, todas de igual forma y color, tantas como cofrades casados, viudos o desposados

\footnotetext{
${ }^{29}$ M.I. FALCÓN PÉREZ, Ordenanzas y otros documentos, doc. 144, pp. 316-324.

${ }^{30}$ Ibidem. p. 321.

${ }^{31} \mathrm{AMZ}$, Actos Comunes de 1440, fol. 21v.
} 
haya, en tres de las cuales meterá una ceduleta con la palabra "elector", dejando las demás vacías. Metidas en un saquete y bien revueltas, las irá entregando por orden a los asistentes, excepto al mayordomo del año anterior, que ejercerá de bolsero en el próximo y a los cofrades solteros. Esta operación la realiza un niño de menos de doce años, acompañado del notario, como es costumbre en todas las elecciones por insaculación. Los tres a los que haya salido el papelito de "elector" se pondrán en pie inmediatamente y se apartarán de los otros, de forma que nadie pueda hablarles, y jurarán en poder del mayordomo del año pasado, que va a ejercer de bolsero en el siguiente, que elegirán a los oficiales del mejor modo que podrán y sabrán, atendiendo a su capacidad y honradez y dejando de lado amistades y odios, y que no saldrán del monasterio hasta haber acabado la elección ${ }^{32}$. A continuación ellos y el notario se apartarán a un lugar donde no puedan ser vistos ni oídos y los tres de acuerdo procederán a la elección de mayordomo compañero del bolsero, consejeros, escribano y limosnero, por este órden. Para todos los cargos los elegidos tienen que estar casados, desposados o ser viudos, pero para el de limosnero elegirán entre los cofrades mozos y solteros. Luego hay unas cláusulas de vacación en el cargo, incompatibilidad de parientes para determinadas funciones y una serie de previsiones para la contingencia de desacuerdo entre los tres electores. Además el documento menciona a un corredor, pero debe de ser permanente, puesto que no se cita entre los elegibles. Finalmente los árbitros derogan una reciente ordenanza municipal que permitía marcar plata de baja ley si era para uso particular en su casa y no para la venta, que había conducido a numerosos fraudes ${ }^{33}$.

Otra parte de la sentencia trata de la comida de hermandad, de quien se ocupará de prepararla, forma de pago a escote por los cofrades, que personas comerán gratis, invitados, de la rendición de cuentas por el mayordomo bolsero, libros de ingresos y gastos competencia del escribano,

\footnotetext{
32"E que los ditos tres electores ni alguno d'ellos no pueda sallir del dito monesterio por sus piedes, ni allenos ni por algun otro engenio o frau fins que la dita eleccion por ellos fazedera sia feyta e acabada". Cfrr. M.I. FALCón PÉREZ, Ordenanzas y otros documentos, doc. 144, p. 311 .

${ }^{33}$ "Que qualquiere argentero ... no pueda obrar en manera alguna obra argent de forga, assi como son plateles, scudiellas, bacines. taças, copas, pigeres, cullaretas e toda otra obra de argent que se acostumbra marcar sing yue sia de leyt de marcar no obstant una ordinacion que los senyores jurados, capitol e consello de la dita ciudat dieron en tiempos passados..." Cfr. M.I. FAlCón PÉREZ, Ordenanzas y otros documentos, doc. 144, p. 312.
} 
y alguna otra cosa de menor importancia, así como la orden de que este reglamento se lea en todos los capítulos de la cofradía.

Un año después de ascender al trono, Juan II vino a Zaragoza ya como nuevo rey, no como lugarteniente de su hermano que había sido hasta junio de 1458. Según costumbre en todas las ciudades, se le ofreció un suntuoso recibimiento, en el que participaron todas las cofradías artesanales junto a los oligarcas concejiles y al pueblo menudo. Los plateros celebraron capítulo el 9 de septiembre de 1459 planteándose lo que habían hecho los argenteros de Valencia en semejante ocasión poco antes, y procurando no ser menos; como era costumbre, designaron una comisión compuesta por los mayordomos y los consejeros para que decidieran junto con los jurados las fiestas o "entremeses" a realizar ${ }^{34}$.

Las noticias acerca de estos profesionales, contratos de aprendizaje, pleitos y una extensa casuística recogidos para el siglo XV son numerosos, pero creo que las aportaciones sustanciales quedan ya dichas. Completamos con un listado de los plateros documentados en Zaragoza en el siglo XV.

${ }^{34}$ AHPZ, Ms. 3952. Protocolo de Pero Martinez de Alfocea, 1459, fols. 129-129v. Entre los comisionados estaba Luis Mallol. 


\section{APÉNDICE}

PROSOPOGRAFÍA (SIGLO XV)

Aguado, Salvador

1459 y 1471

Aguero, Francisco

1461

Aguilar, Gonzalo de: consejero de la cofradía

Ahuero, Francisco: hijo de Pascual Ximénez de Ahuero

Ahuero, Pascual de

Ahuero, Pascual de: árbitro

s.d.'

Ahuero, Pascual Ximenez de (así fig. pp. adelante)

s.d.

Ahuero, Pascual Ximenez de

$1431,1432,1435,1439,1443$

Ahuero, Pascual Ximenez de: fiador de B. Caortiga

1.440

Ahuero, Pascual Ximenez de: muere (c. 23 oct.)

1443

Ahuero, Pascual Ximenez de: trabaja para Dalmau de Mur

$1442-1443$

Albalat, Sthephan

1420

Alpicar, Johan de

1420

Álvarez, García: consejero de la cofradía

1440

Argent, Pedro

1459 y 1471

1460

Artaiz, Johan

1420

errando de

1420

1420

1412

Bosit, Guillem

1420 y 1440

Bover, Johan: marcador (los dos años)

Bruxelas, Johan de (hace el nuevo punzón)

1471

1438

Canal, Arnau

1443

Canale, Arnalt (testigo boda hija B. Cahortiga)

1431

Cardices, Domingo

1476

Duenyas, Alvaro (aprendiz)

1477

1464

is (encargo cruz Tarazona)

1412

Fabra, Jayme

1459 y 1471

Fagot, Johan

'S.d. hace referencia al documento del AHPZ que yo he fechado en 1443, antes de octubre. 
Felices, Pedro

Fermosa, Rodrigo

Ferrando, Bernart (encargo báculo Tarazona)

1459 y 1471

1461

Ferrando, Bernart

1420

Ferrando, Bernart: mayordomo

1442

Ferraz, Juan de (aprendiz

Ferrer, Johan (aprendiz)

Figueras, Johan

Forcen, Manuel

Fortun, Manuel

Frago, Johan del: mayordomo

Frago, Johan del, escudero: mayordomo bolsero

Frago, Johan del

Frago, Johan del (recibe encargo cruz Almuniente)

Garces, Juan

Gibiol, Ginot

Granyen, Martin

Jijon, Juan de (encargo custodia S. Pedro el Viejo)

Johan de Ferraz (aprendiz)

Lenas, Pere

Lion Suslarosa, Anthonico (aprendiz)

Mallol, Luis, bolsero

Mallol, Luis, mayordomo y marcador

Mallol, Luis, padre (diputado para el punzón) 1471

Mallol, Luis, padre: aun vive este año

Mallol, Luis, marcador: muere este año

Mallol, Juan (hijo de Luis Mallol, menor)

Mançana, Pedro (recibe encargo cruz Burbáguena

Mançana, Pere (aprendiz)

Marcen, Lazaro

Marti, Gonçalbo

Martin, Andreu, marcador

Martin, Francisco

1471 y 1472

Martinez, Johan (aprendiz)

Mayor, Johan, marcador

1468 y 1469

Moliner, Guillem (aprendiz)

Monreal, Miguel (relicario cabeza Sta. Engracia)

1457

1466

Monreal, Miguel de (pelea con B. Caortiga)

1446

Monzon, Pedro

459 y 1471

Nadal, Jayme

s.d.

Nadal, Jayme: (se casa) 
Nadal, Jayme: marcador (en sustitución de Luis Mallol)

Nadal, Jayme: mayordomo

Nadal, Jayme, marcador

Nerguer, Bertholomeu

Pérez de Magallón, Esteban

Pisa, Johan de: árbitro

Pisa, Johan de: renuncia a infanzonía

Pisa, Johan: consejero de la cofradía

Prado, Juan del

Puch, Johan

Pujades, Gabriel

1459 y 1471

Roch, Matheo: consejero de la cofradía

Roqua, Bernat (aprendiz)

1431

$\begin{array}{ll}\text { Salinas, Diego de (aprendiz) } & 1473\end{array}$

Salvador, Pascual 1446

Salvador, Pascual: mayordomo s.d.

Salvador, Pascual: mayordomo y marcador 1468

Salvador, Pascual: marcador $\quad 1469$

$\begin{array}{ll}\text { Sanchez, Juan } & 1434\end{array}$

$\begin{array}{ll}\text { Sanchez, Pero: marcador } & 1468\end{array}$

Sanchez, Pedro (encargo cruz S. Andrés) 1473

Sanchez, Alvaro, ya muerto, fue bolsero s.d.

Sanchez, Alvaro: mayordomo $\quad 1440$

Sanchez, Alvaro: mayordomo bolsero 1420

Sanchez, Johan

Sanchez, Pedro (hijo de converso)

s.d., 1434 y 1440

1460-1485

$\begin{array}{ll}\text { Sanchez, Pedro } & 1471 \\ \text { Sanchez, Rodrigo (árbitro pleito entre plateros) } & 1460\end{array}$

Sanginet, Bernat de $\quad 1459$ y 1471

Santa Fe, Garcia de: marcador $\quad 1472$

Santafe, Jayme $\quad 1459$ y 1471

Siscar, Johanico (aprendiz) 1471

Spelt, Frances: marcador $\quad 1415$

Spelt, Frances 1442

$\begin{array}{lr}\text { Tahuenca, Martin de } & 1420\end{array}$

Tudela, Anthon $\quad 1442$

Tudela, Anthon de 1420

Vilanova, Jaime, alias Ceciliano 1431, 1439, 1446, 1459, 1471 y 1476

Vilar, Paulo

Vilar, Paulo: marcador

1468 y 1469

Viola, Nicolau (napolitano) 


\section{RÉSUMÉ}

Étude de l'art de l'orfèvrerie à Saragosse à la fin du Moyen Âge. Une analyse est faite sur les préceptes relatifs aux aspectes techniques du métier, laissant de côté, pour être bien connu de tous, le labeur bénéfique et social de la Confrérie de Saint Eloi, fondée par la reine Marie, lieutenant d'Alphonse V le Magnanime, le 2 Août 1420.

\section{SUMMARY}

This is a study of the jewellery in the city of Zaragoza at the end of the Middle Ages. In this paper, a special attention is given to the regulations concerning the technical aspects of the trade, leaving aside the role played by the Fraternity St. Eloy as a charitable organization, which was founded by the Queen Maria, Lieutenant of Alfonso V, on August 2nd. 1420 . 